Revista Perspectivas Online: Exatas \& Engenharias Anais do V Seminário P\&D PROVIC/PIBIC

II Encontro de Iniciação Científica CNPq Vol. 10, n² 29, Suplemento, 2020

\title{
Avaliação das propriedades mecânicas de um compósito de micélio
}

\author{
Vivyan Pinheiro Simão Ribeiro ${ }^{1}$, Maria das Graças Machado Freire ${ }^{2}$, Vicente Mussi-Dias ${ }^{2}$, \\ Michel Picanço Oliveira ${ }^{3}$, Lucivan Pereira Barros Junior ${ }^{4}$, Bárbara Ferreira de Oliveira ${ }^{5}$ \\ (1) Bolsista de Iniciação Científica do PIBIC/ISECENSA - Curso de Engenharia Civil; (2) Pesquisadores Coladoradores - Laboratório de Química e \\ Biomoléculas-LAQUIBIO/ISECENSA; (3) Pesquisador Colaborador - Laboratório de Mecânica e Materiais/UFES; (4) Pesquisador Colaborador - \\ UFSCAR; (5) Professora Orientadora - Laboratório de Análise e Projeto de Sistemas Mecânicos - LAPSIM/ISECENSA - Institutos Superiores de \\ Ensino do CENSA - ISECENSA, Rua Salvador Correa, 139, Centro, Campos dos Goytacazes, RJ, Brasil
}

O aumento da conscientização sobre a escassez de recursos naturais impulsiona o interesse pelo uso de materiais de base biológica nas indústrias automobilística, civil, design e de embalagens. O emprego de fibras naturais já ocorre em alguns biocompósitos, tendo em vista características como baixo custo, baixa densidade e alta resistência específica. No entanto, comumente as matrizes destes compósitos são fabricadas de compósitos de polímeros sintéticos, geralmente derivados de recursos não-renováveis, de alto impacto ambiental e alta pegada de carbono. Neste contexto, biocompósitos constituídos de uma matriz de micélio, totalmente biodegradável e renovável, têm sido desenvolvidos. Este trabalho visa estudar as propriedades mecânicas de compósitos à base de bagaço de cana-de-açúcar, pó de serra e farelo do trigo e do micélio do fungo Pyconoporus sanguineus. Para fabricação dos corpos de prova, serão utilizados moldes de polietileno tereftalato de etileno glicol previamente esterilizados, onde o substrato com o fungo $P$. sanguineus crescido será disposto com orientação aleatória e prensado manualmente. Após secagem, a análise morfológica do compósito e dos seus componentes individuais será realizada a partir da técnica de microscopia eletrônica de varredura. Sete corpos de provas serão ensaiados para avaliar o comportamento mecânico em flexão e compressão. A partir dos resultados dos ensaios, as propriedades mecânicas serão determinadas e analisadas estatisticamente. Pretende-se desenvolver um compósito que se degrade quando descartado na natureza, após o tempo de vida útil e revele propriedades mecânicas para substituir materiais que não sejam completamente sustentáveis utilizando substratos agrícolas encontrados com facilidade.

Palavras-chave: Sustentabilidade. Ecoprodutos. Micocompósito.

Instituição de Fomento: PIBIC; ISECENSA. 